\title{
Current review on COVID-19 pandemic: a global perspective
}

\author{
Hyma Sara Varghese*
}

Department of Pharmacology, The Oxford College of Pharmacy, Bengaluru, Karnataka, India

Received: 01 June 2020

Revised: 22 June 2020

Accepted: 23 June 2020

*Correspondence:

Mrs. Hyma Sara Varghese,

Email: hyma.sara@gmail.com

Copyright: (C) the author(s), publisher and licensee Medip Academy. This is an open-access article distributed under the terms of the Creative Commons Attribution Non-Commercial License, which permits unrestricted non-commercial use, distribution, and reproduction in any medium, provided the original work is properly cited.

\begin{abstract}
COVID-19 is a serious infectious disease caused by the novel corona virus, SARS-CoV2, threatening the public health with high transmission rate of infection causing more deaths across the globe in elderly population, immunocompromised individuals and in patients with comorbid conditions. At this point of uncertainty, understanding the pandemic challenges is most essential. As very few literature are becoming available in detailing the different perspectives of the disease, this paper presents the readers with current clinical spectrum of infection like details on epidemiology, pathogenesis, manifestations, diagnostic criteria, treatments and preventive measures of this new type of coronavirus.
\end{abstract}

Keywords: COVID-19, SARA-CoV-2, Pandemic, Epidemic, Disease, Infection

\section{INTRODUCTION}

Coronaviruses are a group of viruses that can cause infectious disease in both animals and humans. The severe acute respiratory syndrome (SARS) virus strain known as SARS-CoV is an example of a coronavirus. The new strain of coronavirus is called severe acute respiratory syndrome coronavirus 2 (SARSCoV-2). The virus causes coronavirus disease 19 (COVID-19). The new coronavirus has spread rapidly in many parts of the world. On 11 March 2020, the World Health Organization (WHO) declared COVID-19 a pandemic. Coronaviruses are common in certain species of animals, such as cattle and camels. Although the transmission of coronaviruses from animals to humans is rare, this new strain likely came from bats, though one study suggests pangolins may be the origin. ${ }^{1,2}$

However, it remains unclear exactly how the virus first spread to humans. The graphical representation of the disease transmission is shown in Figure 1.,
Coronaviruses have caused two large-scale pandemics in the past two decades, SARS and Middle East respiratory syndrome (MERS). ${ }^{3}$ The $2019-\mathrm{nCoV}$ has close similarity to bat coronaviruses, and it has been postulated that bats are the primary source. While the origin of the 2019$\mathrm{nCoV}$ is still being investigated, current evidence suggests spread to humans occurred via transmission from wild animals illegally sold in the Huanan seafood wholesale market. $^{4}$

The new coronavirus, SARS-CoV-2, shares high sequence identity to SARS-CoV and a bat coronavirus RaTG13. ${ }^{5}$ While bats may be the reservoir host for various coronaviruses. ${ }^{1}$ Whether SARS-CoV-2 has other hosts remains ambiguous. In one of the recent investigations, one coronavirus isolated from a Malayan pangolin showed $100 \%, 98.6 \%, 97.8 \%$ and $90.7 \%$ amino acid identity with SARS-CoV-2 in the E, M, N and S genes, respectively. ${ }^{2}$ 


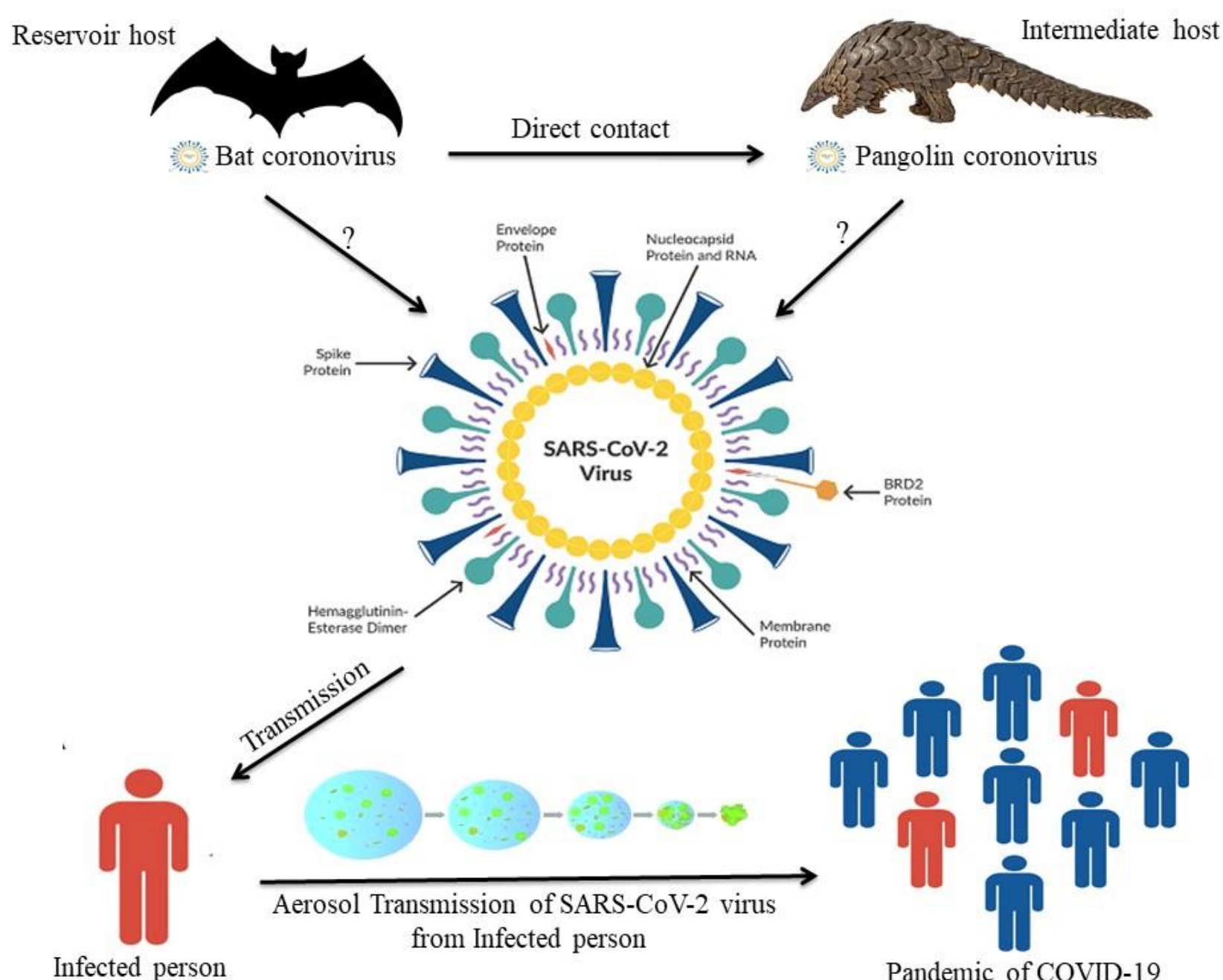

Figure 1: Transmission cycle of SARS-CoV-2.

This virus was reported to be a member of the b group of coronaviruses. The novel virus was named as Wuhan coronavirus or 2019 novel coronavirus (2019-nCov) by the Chinese researchers. Wuhan an emerging business hub of China experienced an outbreak of a novel coronavirus that claimed many lives within the four months of the epidemic. ${ }^{6}$ Patient's clinical manifestations included fever, non-productive cough, dyspnea, myalgia, fatigue, normal or decreased leukocyte counts, and radiographic evidence of pneumonia. Organ dysfunction (eg, shock, acute respiratory distress syndrome ARDS, acute cardiac injury, and acute kidney injury and death can occur in severe cases. ${ }^{7}$ COVID-19 presents a major threat to global public health. This article reviews the current global state, epidemiological outlook, genomic configuration of SARS-CoV-2, molecular mechanisms of pathogenesis, clinical characteristics, diagnostic criteria, preventive measures and management options in order to help follow-up research, prevention and treatment, and to provide readers with the current understanding of this new infectious disease.

\section{EPIDEMIOLOGICAL OUTLOOK}

While SARS resulted in 8096 morbidities and 774 mortalities in 2003 and the Middle East respiratory syndrome (MERS) resulted in 2494 cases and 858 deaths since 2013 till present. ${ }^{8,9}$ The current figures of SARSCoV-2 pandemic are clearly in agreement with the unprecedented outbreak created way more chaos than the infections caused by the former strains of coronaviruses. The chronology of COVID-19 infections is as follows. The first cases were reported in December 2019. ${ }^{10}$ From 18 December 2019 through 29 December 2019, five patients were hospitalized with acute respiratory distress syndrome and one of these patients died. ${ }^{11}$ By 2 January 2020, 41 admitted hospital patients had been identified as having laboratory confirmed COVID-19 infection, less than half of these patients had underlying diseases, including diabetes, hypertension, and cardiovascular disease. $^{7}$ These patients were presumed to be infected in that hospital, likely due to nosocomial infection through unknown mechanisms. This disease outbreak which started from a local seafood market has grown 
substantially to infect 84,970 people in China as shown in (Figure 2) and is associated with 4,645 deaths as of 20 June $2020 .^{12}$

Till 29th of February 2020, there was steep rise in the number of COVID cases in China. However, a reduction in the rate of new cases began to decline resulting in a plateau of the curve for the total number of cases. According to WHO situation reports, by 20th of June 2020, the SARS-CoV-2 pandemic has affected 8,525,042 case individuals, confirmed cases as shown in (Figure 2) and claimed 456,973 lives globally. ${ }^{12}$ The SARS-CoV-2 has been transmitted to more than 215 countries thus far with dreadful impact in almost all affected regions of the world defined by the WHO.

\section{GENOMIC CONFIGURATION OF SARS-CoV-2 AND VIRAL FACTORS}

Coronavirus name derived from the Latin corona, meaning crown. Viral envelope under electron microscopy appears crown-like due to small bulbar projections formed by the viral spike (S) peplomers. Coronaviruses are positive sense, single-strand enveloped RNA viruses belonging to the family Coronaviridae with a diameter of 80-120 nm. ${ }^{13}$ Human coronaviruses can be classified based on human infectivity in to six types such as HCoV-229E, HCoV-OC43, SARS-CoV, NL63/NL/New Haven coronavirus, HKU1-CoV, novel coronavirus 2012 (HCoV-EMC), SARS-CoV-2, MERSCoV. ${ }^{14}$

The genome sequence homology of SARS-CoV-2 and SARS is approximately $80 \%$. SARS-CoV-2 is closer to the SARS-like bat coronaviruses than SARS-CoV, which descended from SARS-like bat coronaviruses. ${ }^{15}$ The structural proteins are encoded by the four structural genes, including spike (S), envelope (E), membrane (M) and nucleocapsid (N) genes as shown in (Figure 3). The orflab is the largest gene in SARS-CoV-2 which encodes the pplab protein and 15 NSPS. The orf1a gene encodes for pp1a protein which also contains 10 NSPS. ${ }^{8,15}$ Interestingly several analyses have shown that SARSCoV-2 uses angiotensin converting enzyme 2 (ACE2) as its receptor, in common with SARS CoV. ${ }^{16}$ Coronaviruses mainly recognize their corresponding receptors on target cells through $\mathrm{S}$ proteins on their surface, entry to the cells results in infection. A structure model analysis shows that SARS-CoV-2 binds to ACE2 with more than 10 folds higher affinity than SARS-CoV, at a level above the threshold required for virus infection. ${ }^{17}$ These results explain the faster transmission capability of SARS-CoV-2 in humans compared with SARS-CoV, and the higher number of confirmed cases of COVID-19 compared with SARS-CoV infection. Considering the higher affinity of SARS-CoV-2 binding to ACE2, soluble ACE2 may be potential candidate for the treatment of COVID-19. ${ }^{18}$

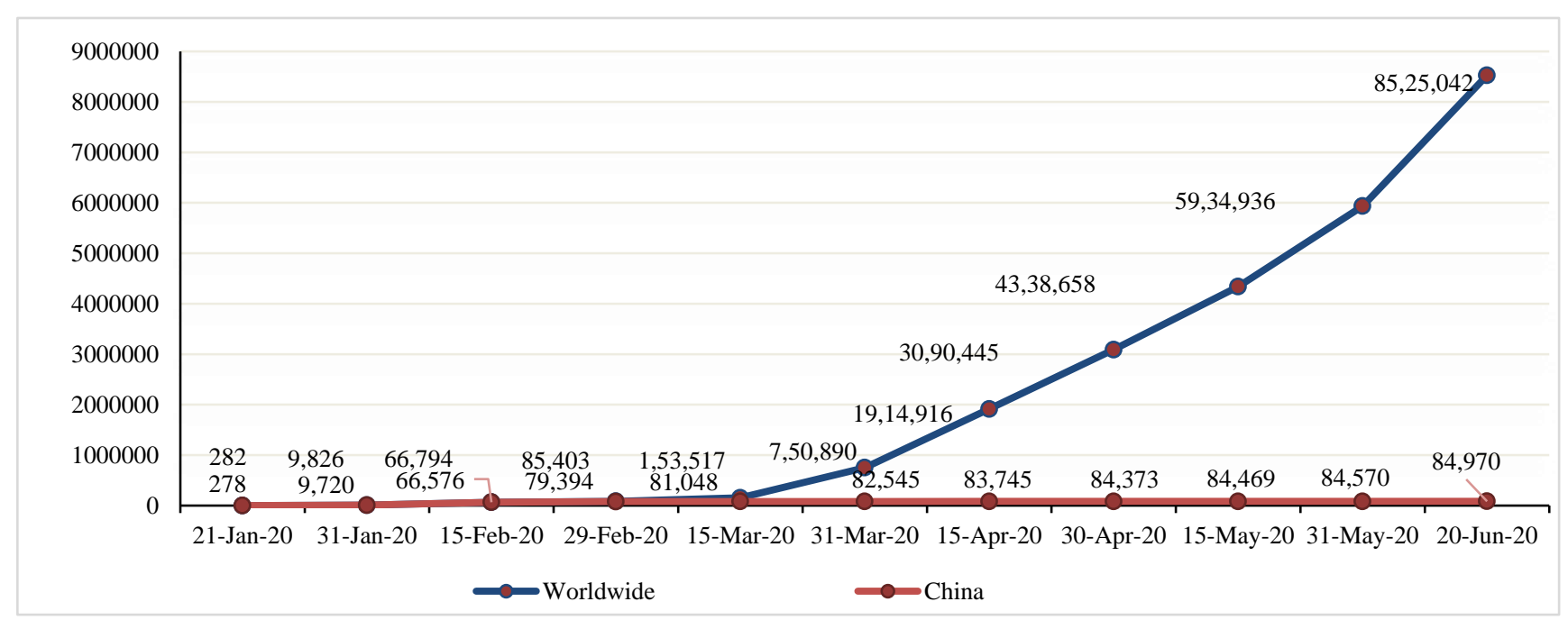

Figure 2: COVID-19 confirmed cases in China and Worldwide as of 20th June 2020.

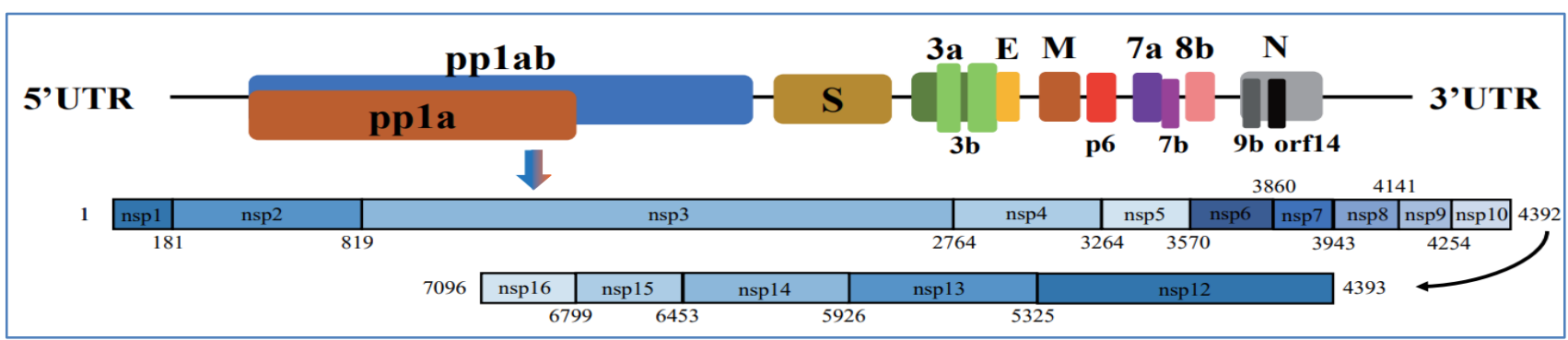

Figure 3: Schematic representation of the genome composition of SARS-CoV-2, studied by Wu et al. ${ }^{15}$ 


\section{MOLECULAR MECHANISMS OF PATHO- GENESIS AND VIRAL REPLICATION}

ACE2, which is present in the human's lower respiratory tract, is the well-known receptor utilized by SARS-CoV and controls both human-to-human and cross-species transmission. ${ }^{7,19}$ One of the recent studies confirmed that SARS-CoV-2 present in the bronchoalveolar lavage fluid (BALF) of a COVID-19 infected patient also utilizes the ACE2 cellular receptor. ${ }^{5}$ The S-glycoprotein of the Coronavirus can bind to the ACE2 receptor of the human respiratory cells. The S-glycoprotein has two subunits; S1 and $\mathrm{S} 2$, as shown in (Figure 3 ). ${ }^{20}$ While $\mathrm{S} 1$ regulates the cellular tropism, the virus and host range, S2 facilitates virus and cell membrane fusion through tandem domains; heptad repeats 1 (HR1) and HR2 membrane fusion results in release of the viral RNA into the cytoplasm and the RNA (uncoated) encode two polyproteins; ppla and pplab, which translate the NSP sequence, and collectively make replication-transcription complex (RTC) in double-layered vesicle. ${ }^{21,23}$ RTC continuously replicates and form a network of sub-genomic RNAs, which translates structural and accessory proteins. ${ }^{24}$ These envelope glycoproteins, nucleocapsid proteins and new genomic RNA amalgamate together to produce virus particles. Finally, the vesicles containing virion fuse with the cell membrane to discharge the new viruses.

Virions are then released from the infected cell through exocytosis. The released viruses can infect kidney cells, liver cells, intestines, and T lymphocytes, as well as the lower respiratory tract, where they form the main symptoms and signs. ${ }^{25}$ The main pathogenesis of COVID-19 infection as a respiratory system targeting virus was severe pneumonia, RNA anemia, combined with the incidence of ground-glass opacities, and acute cardiac injury. Patients infected with COVID-19 showed higher leukocyte numbers, abnormal respiratory findings, and increased levels of plasma pro-inflammatory cytokines. Significantly high blood levels of cytokines and chemokines were noted in patients with COVID-19 infection that included IL1- $\beta$, IL1RA, IL7, IL8, IL9, IL6, IL10, basic FGF2, GCSF, GMCSF, IFN $\gamma$, IP10, MCP1, MIP1 $\alpha$, MIP1 $\beta$, PDGFB, TNF $\alpha$, and VEGFA. Some of the severe cases that were admitted to the intensive care unit showed high levels of pro-inflammatory cytokines including IL2, IL7, IL10, GCSF, IP10, MCP1, MIP1 $\alpha$, and TNF $\alpha$ that are reasoned to promote disease severity. ${ }^{7}$ Since SARS-CoV-2, S-glycoprotein and ACE2 receptor binding is necessary for the entry of the virus, virusreceptor drug target research is one of the potential therapeutic approaches.

\section{TRANSMISSION AND HIGH-RISK POPULATION}

Based on the available evidence, large number of infected people were those exposed to the wet animal market in Wuhan city where live animals are routinely sold, which suggests that COVID-19 to be of zoonotic origin. ${ }^{26}$ From the recent studies, it has been observed that the novel virus causing epidemics coincides with the $\mathrm{CoV}$ isolated in bats. Genomic sequence analysis of COVID-19 showed $88 \%$ identity with two bat-derived SARS-like coronaviruses, indicating that mammals are the most likely link between COVID-19 and humans. ${ }^{8}$ Several reports have suggested that person-to-person transmission is a likely route for spreading COVID-19 infection.

Depending on available evidence of genome sequencing and evolutionary analysis, bat has been suggested as the natural reservoir and origin of the SARS-CoV2. Bats may transmit the virus to humans via anonymous intermediate hosts, ${ }^{19}$ Lately, pangolin has also been suggested to play a role in the viral infection as an intermediate host because about $99 \%$ of sequence similarity exist between pangolin species >1000 samples metagenomic data and SARSCoV-2 confirmed reports from many infected healthcare workers in Wuhan show that human-to-human transmission can occur. Often, the human-to-human transmission occurs with close contact. The transmission is primarily through respiratory droplets while coughing and/or sneezing. Transmission through droplet can take place when a COVID-19 person coughs or sneezes, as a result of which SARS-CoV-2 containing droplets are pushed up to 3 feet. ${ }^{19}$ These droplets can settle in the mouth or nasal mucosa and lungs of people with inhaled air. A recent study reported that ocular surface does have the potential to carry SARS-CoV-2 and therefore can transmit the infection. ${ }^{27}$ Other means of SARS-CoV-2 spread include handshaking with infected person, contact with an object/surface containing virus, repeated touching of the face, eyes, nose or mouth or exposure to stool, saliva, urine sample of infected patient. ${ }^{28}$ Also, the presence of SARS-CoV-2 in semen of infected patients was reported. ${ }^{29}$ However, several studies have reported that a substantial percentage of COVID-19 occurrence are in patients who had underlying comorbidities. ${ }^{7,28,30}$

Table 1: COVID-19 fatality rate by age in China.

\begin{tabular}{|l|l|}
\hline Age in years & $\begin{array}{l}\text { Death rate (as of 11 } \\
\text { February 2020) in \% }\end{array}$ \\
\hline $\mathbf{8 0 +}$ & 14.8 \\
\hline $\mathbf{7 0 - 7 9}$ & 8.0 \\
\hline $\mathbf{6 0 - 6 9}$ & 3.6 \\
\hline $\mathbf{5 0 - 5 9}$ & 1.3 \\
\hline $\mathbf{4 0 - 4 9}$ & 0.4 \\
\hline $\mathbf{3 0 - 3 9}$ & 0.2 \\
\hline $\mathbf{2 0 - 2 9}$ & 0.2 \\
\hline $\mathbf{1 0 - 1 9}$ & 0.2 \\
\hline
\end{tabular}

For instance, it was demonstrated that $50.5 \%$ of COVID19 patients had chronic health conditions, which included cerebrovascular and cardiovascular diseases reported at least one comorbid condition among $23.2 \%$ of the COVID-19 cases. $^{28,31}$ Among coexisting diseases, Hypertension was the most frequent illness $14.9 \%$, followed by diabetes mellitus $7.4 \% .{ }^{28}$ Likewise, a report from China centre for disease control (CDC) weekly also revealed hypertension as the most prevalent underlying health condition $12.8 \%$, followed by diabetes mellitus $5.3 \%$ and cardiovascular disease $4.2 \%$ in COVID-19 
patients. The earlier deaths reported due to COVID-19 have also been attributed to old age as outlined in (Table 1) and comorbid conditions as shown in (Figure 4), perhaps owing to immune suppression that allows virus to reproduce at much higher rate. ${ }^{30}$

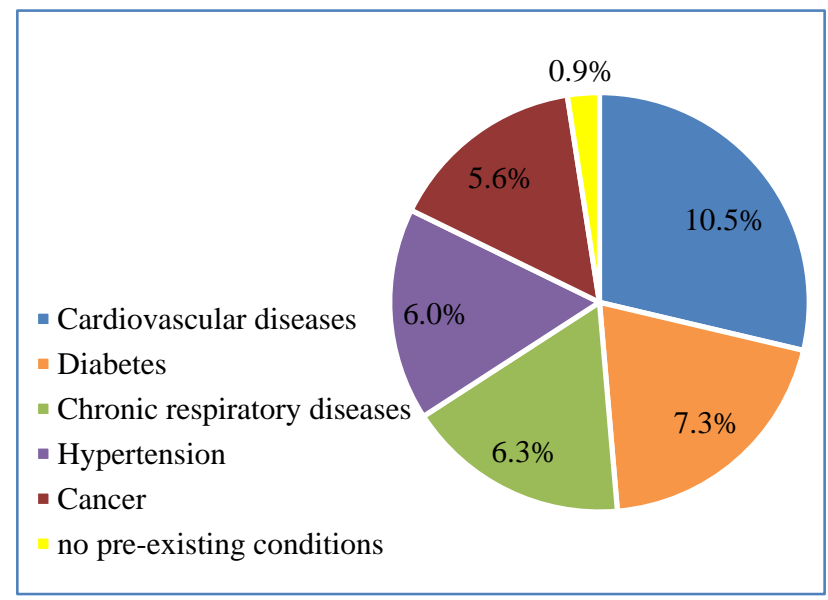

Figure 4: COVID-19 fatality rate by comorbidity in China.

\section{CLINICAL FEATURES AND DIAGNOSTIC CRITERIA}

The acute viral infection produced by SARS-CoV-2 in humans pronounces significant degree of clinical features which is similar to SARS-CoV with an incubation period of 2-14 days. $~ 80-90 \%$ of infections are not severe and many may be asymptomatic. The most common symptoms of COVID-19 are fever 44-98\%, cough 46$82 \%$, usually dry), shortness of breath at onset $31 \%$, myalgia or fatigue $11-44 \%$, similar to other coronavirus infections. Most patients are prone to several variety of complications, including acute respiratory distress syndrome, acute heart injury and secondary infection. ${ }^{32}$ There is already some evidence that COVID-19 can cause damage to tissues and organs other than the lungs. ${ }^{33} \mathrm{~A}$ case report of the pathological manifestations of a patient with pneumonia showed moderate micro-vesicular steatosis in liver tissue. ${ }^{34}$ Recent study reported that $90 \%$ of patients had bilateral chest CT findings, and the sensitivity of chest CT to suggest COVID-19 was $97 \% .{ }^{35}$ Combining chest CT imaging features with clinical symptoms and laboratory tests could facilitate early diagnosis of COVID-19 pneumonia. Laboratory examination revealed that $82.1 \%$ of patients were lymphopenic and $36.2 \%$ of patients were thrombocytopenic. Most patients had normal leukocytes, but leukopenia was observed in $33.7 \%$ of patients. $^{7}$ In addition, most patient's demonstrated elevated levels of C-reactive protein, lactate dehydrogenase and creatinine kinase, but a minority of patients had elevated transaminase, abnormal myocardial enzyme spectrum or elevated serum creatinine. In comparison with bacterial pneumonia, patients with COVID-19 had a lower oxygenation index. Cytokine release syndrome is a vital factor that aggravates disease progression. Higher levels of interleukin IL-6 and IL-10, and lower levels of CD4+T and CD8+T have been observed in patients with COVID19, correlated with the severity of disease. ${ }^{36}$ Histopathological examination of the samples from pulmonary biopsy showed that the patient's lung was predominated with diffuse alveolar damages, including disrupt of alveolar septa, proliferation and desquamation of type-II alveolar epithelial cells, exudation of fibrin, monocytes and macrophages, and formation of hyaline membrane as shown in Figure 5.37 These pulmonary pathologic features were consistent with those seen in SARS and MERS. ${ }^{34,37,38}$

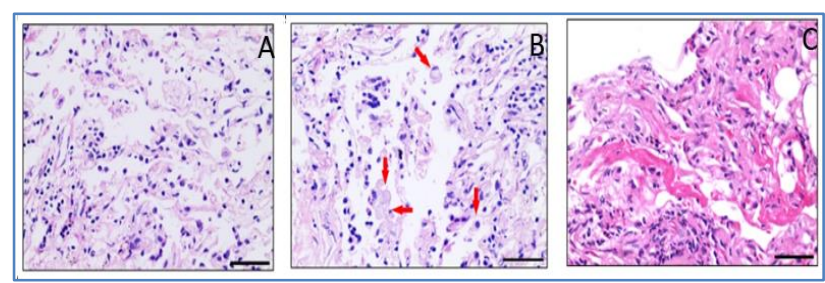

Figure 5: Histopathological changes of COVID-19 in the pulmonary tissues of mild and recovering patients, studied by Yao et al. (A) $\mathbf{H}$ and $\mathrm{E}$ staining shows desquamated and enlarged epithelial cells, (B) $\mathrm{H}$ and E staining shows exudative monocytes/macrophages in alveoli; red arrows show typical macrophages in alveoli and (C) $\mathrm{H}$ and $\mathrm{E}$ staining shows formation of hyaline membranes.

Table 2: Diagnostic criteria for COVID-19.

\begin{tabular}{|c|c|}
\hline Clinical features & Epidemiologic risk \\
\hline \multirow{3}{*}{$\begin{array}{l}\text { Fever and } \\
\text { symptoms of lower } \\
\text { respiratory illness } \\
\text { (e.g., cough, } \\
\text { difficulty } \\
\text { breathing) }\end{array}$} & $\begin{array}{l}\text { Close contact with a person } \\
\text { who is under investigation for } \\
2019-\mathrm{nCoV} \text { while that person } \\
\text { was ill in the last } 14 \text { days } \\
\text { before symptom onset }\end{array}$ \\
\hline & - or - \\
\hline & $\begin{array}{l}\text { Travel history from affected } \\
\text { geographic areas within } 14 \\
\text { days of symptom onset }\end{array}$ \\
\hline $\begin{array}{l}\text { Fever or } \\
\text { symptoms of lower } \\
\text { respiratory illness } \\
\text { (e.g., cough, } \\
\text { difficulty } \\
\text { breathing) }\end{array}$ & $\begin{array}{l}\text { Any person who has had close } \\
\text { contact with a laboratory } \\
\text { confirmed COVID-19 patient } \\
\text { within } 14 \text { days of symptom } \\
\text { onset }\end{array}$ \\
\hline
\end{tabular}

As in SARS and MERS, the diagnosis of $2019 \mathrm{n}-\mathrm{CoV}$ infection is based on a history of detailed contact and travel, and precise laboratory testing, as detailed in Table 2. The diagnostic tools are molecular methods, serology and viral culture. The most common diagnostic methods are molecular methods as RT-PCR (reverse transcription) or real-time PCR, which are made using RNA from respiratory samples such as oropharyngeal swabs, sputum, nasopharyngeal aspirate, deep tracheal aspirate, 
or bronchoalveolar lavage. In particular, lower respiratory tract samples can offer significantly higher viral load and genome fraction than upper respiratory tract samples. These techniques are beneficial in terms of evaluating the results quickly, showing the genome structure and viral loads. ${ }^{39}$

\section{PREVENTION AND MANAGEMENT}

Finding effective ways to prevent the spread of SARSCoV-2 remains a global challenge. Governments, public bodies, and other organizations are also taking measures to prevent the spread of SARS-CoV-2. For individuals, taking protective measures can effectively prevent SARSCoV2 infection, including hand washing with soap or an alcohol-based hand rub, regularly disinfecting surfaces with $70 \%$ ethyl alcohol or $0.5 \%$ bleach solution, refraining from touching eyes, nose and mouth with soiled hands, exercising respiratory hygiene such as coughing or sneezing into a bent elbow or tissue, disposing contaminated tissue immediately, wearing medical or surgical mask for individuals with respiratory symptoms, performing hand hygiene after disposing off medical or surgical mask, self-quarantining of individuals with respiratory symptoms, confining the elderly people to homes, avoiding close contact in large gatherings and maintaining a person-to-person distance of 6.5 feet, drinking plenty of water, avoiding smoking, travel screening, worldwide travel ban, closure of educational institutions, working from home wherever possible and remaining abreast of the developing situation regarding SARS-CoV-2. The key to boost personal immunity is to maintain personal hygiene, a healthy lifestyle and adequate nutritional intake. ${ }^{40}$ Studies have shown that vitamin C may prevent the susceptibility of lower respiratory tract infection under certain conditions, while COVID-19 may cause lower respiratory tract infection. ${ }^{41}$ Therefore, a moderate amount of vitamin $\mathrm{C}$ supplementation may be a way to prevent COVID-19.

Many viruses are preventable through antiviral vaccinations. However, it takes time to develop and distribute safe and effective vaccines. A vaccine for COVID-19 is unlikely to be available any time soon. Current therapeutic options mostly focused on symptomatic and supportive management of COVID-19 as per recent guidelines. ${ }^{42}$ Remdesivir has been reported as a promising antiviral drug against a wide array of RNA viruses. Holshue et al reported that treatment of a patient with COVID-19 with remdesivir achieved good results, remdesivir receives U.S. food and drug administration emergency use authorization (EUA) for the treatment of hospitalized 2019 coronavirus disease (COVID-19) patients on 1 May 2020 as briefed in Table 3.43,44

Meanwhile, an antimalarial drug hydroxychloroquine treatment showed significant reduction in the viral load in twenty COVID-19 treated patients and its effects were reinforced by azithromycin. ${ }^{45}$

Table 3: Emergency use authorization for use of remdesivir to treat hospitalized patients with COVID-19.

\begin{tabular}{|lll|}
\hline Patient condition & Treatment duration & Dose and route of administration \\
\hline $\begin{array}{l}\text { Receiving mechanical ventilation } \\
\text { or extracorporeal membrane } \\
\text { oxygenation (ECMO) }\end{array}$ & 10 days & Day 1 (loading dose): Remdesivir 200 mg IV \\
\hline $\begin{array}{ll}\mathrm{SaO}_{2} \leq \mathbf{9 4 \%} \text { on room air or } \\
\text { supplemental oxygen required }\end{array}$ & $\begin{array}{l}\text { 5 days; if no improvement } \\
\text { after 5 days, continue for } \\
\text { an additional 5 days }\end{array}$ & Days 2 through 9: Remdesivir 100 mg IV daily \\
\cline { 2 - 3 } & & Day 2 through 5: Remdesivir 100 mg IV daily \\
\hline
\end{tabular}

Table 4: COVID-19 vaccines in clinical trials.

\begin{tabular}{|llll|}
\hline Test vaccine & Developer & Properties & Development status \\
\hline mRNA-1273 & Moderna and NIAID & mRNA vaccine & Phase 2 \\
\hline BNT162 & BioNTech and Pfizer & mRNA vaccine & Phase $1 / 2$ \\
\hline INO-4800 & Inovio pharmaceuticals & DNA vaccine & Phase 1 \\
\hline AZD1222 & University of Oxford and AstraZeneca & Adenovirus vaccine & Phase $2 \mathrm{~b} / 3$ \\
\hline Ad5-nCoV & CanSino Biologics & Adenovirus vaccine & Phase 2 \\
\hline Unnamed & $\begin{array}{l}\text { Wuhan institute of biological products } \\
\text { and Sinopharm }\end{array}$ & Inactivated virus & Phase $1 / 2$ \\
\hline Unnamed & $\begin{array}{l}\text { Beijing institute of biological products } \\
\text { and Sinopharm }\end{array}$ & Inactivated virus & Phase $1 / 2$ \\
\hline PiCoVacc & Sinovac & $\begin{array}{l}\text { Inactivated virus, plus } \\
\text { adjuvan }\end{array}$ & Phase $1 / 2$ \\
\hline Unnamed & $\begin{array}{l}\text { Institute of medical biology and Chinese } \\
\text { academy of medical sciences }\end{array}$ & Inactivated virus & Phase 1 \\
\hline NVX-CoV2373 & Novavax & Protein subunit & Phase $1 / 2$ \\
\hline
\end{tabular}


Another study proved remdesivir and chloroquine combination to be effective in antagonizing the in vitro replication of SARS-CoV-2. ${ }^{46}$ A report from South Korea showed significantly reduced SAR-CoV-2 viral loads in COVID-19 patient upon administration of lopinavir/ritonavir treatment. ${ }^{47}$ Favipiravir, an oral antiviral drug approved for the treatment of influenza which selectively inhibits RNA polymerase, is in phase 3 clinical trial on moderately infected COVID-19 patients. Earlier, a meta-analysis on use of convalescent plasma for SARS-CoV and MERS-CoV infection has shown encouraging results. ${ }^{48}$ In particular, administration of convalescent plasma, obtained from recovered COVID19-infected patients, showed promising results in treating patients with clinical complication related to the infection. Also, plasma and immunoglobulin $\mathrm{G}$ showed promising results in treating severe cases. ${ }^{49}$ Already, ten vaccines against SARS-COV-2 are in clinical trials, and are discussed in detail in Table $4 .{ }^{50}$

\section{CONCLUSION}

The SARS-CoV-2 pandemic has zoonotic origin and patients present with typical pneumonia signs and symptoms. The most encountered deaths were from individual that were elderly, immunocompromised or with existing health conditions. While China might have reached the plateau with regards to incidence of new COVID-19 cases, other countries are still struggling to flatten the curve of reported cases and in fact, numbers of cases and fatalities have surpassed that of China. Till date, no effective therapy is available except for supportive disease management. However, the similarity of genomic sequences between SARS-CoV-2 and SARS$\mathrm{CoV}$ and MERS might assist in development of novel treatments.

Funding: No funding sources Conflict of interest: None declared

Ethical approval: Not required

\section{REFERENCES}

1. Wu F, Zhao S, Yu B, Chen YM, Wang W, Song ZG, et al. A new coronavirus associated with human respiratory disease in China. Nature. 2020;579(7798):265-9.

2. Xiao K, Zhai J, Feng Y, Zhou N, Zhang X, Zou JJ, et al. Isolation of SARS-CoV-2-related coronavirus from Malayan pangolins. Nature. 2020.

3. Zaki AM, Boheemen VS, Bestebroer TM, Osterhaus ADME, Fouchier RAM. Isolation of a novel coronavirus from a man with pneumonia in Saudi Arabia. N Engl J Med. 2012;367:1814-20.

4. Chen N, Zhou M, Dong X, Qu J, Gong F, Han Y, et al. Epidemiological and clinical characteristics of 99 cases of 2019 novel coronavirus pneumonia in Wuhan, China: a descriptive study. Lancet. 2020;395:507-13.

5. Zhou P, Yang XL, Wang XG, Hu B, Zhang L, Zhang $\mathrm{W}$, et al. A pneumonia outbreak associated with a new coronavirus of probable bat origin. Nature. 2020;579:270-3.

6. Cui J, Li F, Shi ZL. Origin and evolution of pathogenic coronaviruses. Nat Rev Microbiol. 2019;17(3):181-92.

7. Huang C, Wang Y, Li X, Ren L, Zhao J, Hu Y, et al. Clinical features of patients infected with 2019 novel coronavirus in Wuhan, China. Lancet. 2020;395:497506.

8. Lu R, Zhao X, Li J, Niu P, Yang B, Wu H, et al. Genomic characterization and epidemiology of 2019 novel coronavirus: implications for virus origins and receptor binding. Lancet. 2020;395(10224):565-74.

9. $\mathrm{Wu} \mathrm{Z}$, McGoogan JM. Characteristics of and Important Lessons from the Coronavirus Disease 2019 (COVID-19) Outbreak in China: Summary of a Report of 72314 Cases from the Chinese Center for Disease Control and Prevention. JAMA. 2020.

10. Toit ADA. Outbreak of a novel coronavirus. Nat Rev Microbiol. 2020;18:123.

11. Ren LL, Wang YM, Wu ZQ, Xiang ZC, Guo L, Xu $\mathrm{T}$, et al. Identification of a novel coronavirus causing severe pneumonia in human: a descriptive study. Chinese Med J. 2020;133(9):1015-24.

12. WHO, Coronavirus disease 2019 (COVID-19) Situation Report-152; 2020.

13. Chan JF, To KK, Tse H, Jin DY, Yuen KY. Interspecies transmission and emergence of novel viruses: lessons from bats and birds. Trends Microbiol. 2013;21:544-55.

14. Weiss SR, Martin NS. Coronavirus Pathogenesis and the Emerging Pathogen Severe Acute Respiratory Syndrome Coronavirus. Microbiol and Mol Bio Rev. 2005;69(4):635-64.

15. Wu A, Peng Y, Huang B, Ding X, Wang X, Niu P, et al. Genome composition and divergence of the novel coronavirus (2019-nCoV) originating in China. Cell Host Microbe. 2020;27(3):325-8.

16. Hoffmann M, Weber KH, Kruger N, Muller M, Drosten C, Pohlmann S. The novel coronavirus 2019 (2019-nCoV) uses the SARS-coronavirus receptor ACE2 and the cellular protease TMPRSS2 for entry in to target cells. BioRxiv. 2020.

17. Wrapp D, Wang N, Corbett KS, Goldsmith JA, Hsieh CL, Abiona O, et al. Cryo-EM structure of the 2019$\mathrm{nCoV}$ spike in the prefusion conformation. Science. 2020;367(6483):1260-3.

18. Shereena MA, Khana S, Kazmic A, Bashira N, Siddiquea R. COVID-19 infection: Origin, transmission, and characteristics of human coronaviruses. J Adv Res. 2020;24:91-8.

19. Guo YR, Cao QD, Hong ZS, Tan YY, Chen SD, Jin $\mathrm{HJ}$, et al. The origin, transmission and clinical therapies on coronavirus disease 2019 (COVID-19) outbreak: an update on the status. Mil Med Res. 2020;7:11.

20. Tortorici MA, Veesler D. Structural insights into coronavirus entry. Adv Virus Res. 2019;105:93-116.

21. Ji W, Wang W, Zhao X, Zai J, Li X. Cross-species transmission of the newly identified coronavirus 2019nCoV. J Med Virol. 2020;92:433-40. 
22. Zhang CY, Wei JF, He SH. Adaptive evolution of the spike gene of SARS coronavirus: changes in positively selected sites in different epidemic groups. BMC Microbiol. 2006;6:88.

23. Wilde DAH, Snijder EJ, Kikkert M, Hemert VM. Host Factors in Coronavirus Replication. Curr Top Microbiol Immunol. 2008;419:1-42.

24. Hussain S, Pan Ja, Chen Y, Yang Y, Xu J, Peng Y, et al. Identification of Novel Subgenomic RNAs and Noncanonical Transcription Initiation Signals of Severe Acute Respiratory Syndrome Coronavirus. J Virol. 2005;79:5288-95.

25. Lambeir AM, Durinx C, Scharpe S, Meester DI. Dipeptidylpeptidase IV from bench to bedside: An update on structural properties, functions, and clinical aspects of the enzyme DPP IV. Crit Rev Clin Lab Sci. 2003;40:209-94.

26. Chan JFW, Yuan S, Kok KH, Wang KKT, Chu H, Yang J, et al. A familial cluster of pneumonia associated with the 2019 novel coronavirus indicating person-to-person transmission: a study of a family cluster. Lancet. 2020;395:514-23.

27. Lu CW, Liu XF, Jia ZF. 2019-nCoV transmission through the ocular surface must not be ignored. Lancet. 2020;395:39.

28. Guan WJ, Ni ZY, Hu Y. Clinical Characteristics of Coronavirus Disease 2019 in China. N Engl J Med. 2020;382(18):1708-20.

29. Li D, Jin M, Bao P, Zhao W, Zhang S. Clinical Characteristics and Results of Semen Tests Among Men with Coronavirus Disease 2019. JAMA. 2020;3(5):208292.

30. Team T. Vital Surveillances: The Epidemiological Characteristics of an Outbreak of 2019 Novel Coronavirus Diseases (COVID-19) China, 2020. China CDC Weekly 2; 2020:113-22.

31. Wang $\mathrm{D}, \mathrm{Hu} \mathrm{B}, \mathrm{Hu}$ C. Clinical Characteristics of yang Hospitalized Patients With 2019 Novel Coronavirus-Infected Pneumonia in Wuhan, China. JAMA. 2020;323(11):1061-9.

32. Arentz M, Yim E, Klaff L. Characteristics and Outcomes of 21 Critically Ill Patients With COVID19 in Washington State. JAMA. 2020;323(16):16124.

33. Yang Y, Lu Q, Liu M, Wang Y, Zhang A, Jalali N, et al. Epidemiological and clinical features of the 2019 novel coronavirus outbreak in China. Med Rxiv. 2020.

34. Zhe Xu, Lei Shi, Wang Y, Zhang J, Huang L, Zhang $\mathrm{C}$, et al. Pathological findings of COVID-19 associated with acute respiratory distress syndrome. Lancet Respir Med. 2020;8:420-22.

35. Mao L, Wang M, Chen S, He Q, Chang J, Hong C, et al. Neurological manifestations of hospitalized patients with COVID-19 in Wuhan, China: a retrospective case series study; 2020.

36. Wan S, Yi Q, Fan S. Characteristics of lymphocyte subsets and cytokines in peripheral blood of 123 hospitalized patients with 2019 novel coronavirus pneumonia (NCP). Med Rxiv. 2020.
37. Yao X, He Z, Li T Zhang $\mathrm{H}$, Wang Y, Mou $\mathrm{H}$. Pathological evidence for residual SARS-CoV-2 in pulmonary tissues of a ready for discharge patient. Cell Res. 2020.

38. Hwang DM, Chamberlain DW, Poutanen SM, Low DE, Asa SL, Butany J. Pulmonary pathology of severe acute respiratory syndrome in Toronto. Modern Pathol. 2005;18(1):1-10.

39. Zhu N, Zhang D, Wang W. A novel coronavirus from patients with pneumonia in China, 2019. N Engl J Med. 2020;382(8):727-33.

40. High KP. Nutritional strategies to boost immunity and prevent infection in elderly individuals. Clin Infect Dis. 2001;33:1892-900.

41. Hemila H. Vitamin C intake and susceptibility to pneumonia. Pediatr Infect Dis J. 1997;16:836-7.

42. Jin YH, Cai L, Cheng ZS, Cheng H, Deng T, Fan YP, et al. A rapid advice guideline for the diagnosis and treatment of 2019 novel coronavirus (2019-nCoV) infected pneumonia. Mil Med Res. 2020;7(1):4.

43. Holshue ML, Bolt DC, Lindquist, Lofy $\mathrm{KH}$, Wiesman. First case of 2019 novel coronavirus in the United States. N Engl J Med. 2020;382(10):929-36.

44. US Food and Drug Administration, Emergency Use Authorization (EUA) for emergency use of remdesivir for the treatment of hospitalized 2019 coronavirus disease (COVID-19) patients; 2020.

45. Gautret P, Lagier JC, Parola P, Hoang VT, Meddeb $\mathrm{L}$, Mailhe $\mathrm{M}$, et al. Hydroxychloroquine and azithromycin as a treatment of COVID-19: results of an open-label non-randomized clinical trial. Int $\mathbf{J}$ Antimicrob Agents. 2020;20:105949.

46. Wang M, Cao R, Zhang L, Yang X, Liu J, Xu M, et al. Remdesivir and chloroquine effectively inhibit the recently emerged novel coronavirus (2019-nCoV) in vitro. Cell Res. 2020;30:269271.

47. Lim J, Jeon S, Shin HY, Kim MJ, Seong YM, Lee WJ, et al. Case of the Index Patient Who Caused Tertiary Transmission of COVID-19 Infection in Korea: The Application of Lopinavir/Ritonavir for the Treatment of COVID-19 Infected Pneumonia Monitored by Quantitative RT-PCR. J Korean Med Sci. 2020;35:79.

48. Jenkins MJ, Campos SM, Baillie JK, Cleary P, Khaw FM, Lim WS, et al. The effectiveness of convalescent plasma and hyperimmune immunoglobulin for the treatment of severe acute respiratory infections of viral etiology: a systematic review and exploratory meta-analysis. J Infec Dis. 2015;211:80-90.

49. Shen C, Wang Z, Zhao F, Yang Y, Li J, Yuan J, et al. Treatment of 5 critically Ill patients with COVID-19 with convalescent plasma. JAMA. 2020.

50. Mullard A. COVID vaccine development pipeline gears up. Lancet. 2020:395(10239)1751-2.

Cite this article as: Varghese HS. Current review on COVID-19 pandemic: a global perspective. Int J Basic Clin Pharmacol 2020;9:1159-66. 